\title{
Editorial
}

\section{A new era in the treatment of primary pulmonary hypertension}

Primary pulmonary hypertension ( $\mathrm{PPH})$ is a disease associated with significant morbidity and mortality that occurs most commonly in young and middle aged women. ${ }^{1}$ Until recently, there had been only a limited number of therapies available to treat this disease. Over the years, however, endeavours in cellular and molecular research have improved our understanding of this disease process and allowed for the development of targeted approaches to treatment. These new therapies have created an atmosphere of optimism in the management of a disease was considered untreatable.

Pulmonary vasoconstriction was long considered to be the only "treatable" aspect of PPH. Accordingly, the treatment of PPH focused on the administration of oral vasodilators, mainly calcium channel blockers, in the hope of countering the vasoconstrictive process. The treatment of this subset of "vasoreactive" patients with calcium channel blockers has been shown to result in improvements in symptoms, exercise tolerance, cardiopulmonary haemodynamics, and survival. ${ }^{2}$ Unfortunately, only a small number $(20 \%)$ of patients demonstrate a beneficial response to calcium channel blockade and, in fact, calcium blockers lead to numerous adverse effects in "non-responders". Therefore utility of these agents is limited and their use should be confined to those in whom a clear acute vasodilator response is demonstrated haemodynamically.

Looking beyond simple pulmonary vasoconstriction, it is now recognised that defects in endothelial function, pulmonary vascular smooth muscle cells, and circulating blood factors may all be involved in the pathogenesis and progression of $\mathrm{PPH}$. The pathophysiologic and histopathologic consequences of these derangements are complex and variable, but serve as a framework for understanding and treating $\mathrm{PPH}$.

The pulmonary arterial endothelium produces a variety of active mediators which, under normal conditions, tightly regulate pulmonary vascular tone and control smooth muscle cell proliferation, maintaining the pulmonary vasculature in a low pressure state. These "good" mediators include nitric oxide, prostacyclin, and heparinlike mediators. On the "bad" side are mediators favouring pulmonary vasoconstriction and cell proliferation, including endothelin-1, thromboxane, and serotonin.

There is now ample evidence from both animal models and humans with primary and secondary forms of pulmonary hypertension that an imbalance between these "good" and "bad" endothelial derived mediators contributes to the development of pulmonary vasculopathy. It follows then that either replacing the "good" or inhibiting the "bad" might be efficacious.

\section{Prostacyclin}

Circulating concentrations of prostacyclin (PGI2), a potent vasodilating and antiproliferative mediator, are reduced in patients with PPH. ${ }^{3}$ Regardless of whether PGI2 deficiency causes or results from pulmonary vasculopathy, the rationale for replacement treatment exists. Continuous intravenous PGI2 (epoprostenol, Flolan), in fact, has been shown to improve exercise tolerance and pulmonary haemodynamics in patients with both primary ${ }^{4}$ and secondary ${ }^{5}$ forms of pulmonary hypertension, and is the only treatment approved by the US Food and Drug Administration (FDA) for PPH and pulmonary hypertension caused by the scleroderma spectrum of disease. An interesting aspect of epoprostenol efficacy is that, in some patients, long term decreases in pulmonary arterial pressure occur despite lack of any acute vasodilator response, suggesting a beneficial remodelling effect on the pulmonary vasculature. Survival is also improved in PPH.

The difficulties with delivering intravenous prostacyclin chronically are substantial and have stimulated interest in devising stable analogues of this compound that can be administered using less complex delivery systems. Trials evaluating the safety and effectiveness of inhaled, subcutaneous, and oral delivery of prostacyclin are currently underway.

A large study examining the efficacy of a subcutaneous analogue of prostacyclin (Uniprost) was recently completed. In a 12 week trial, patients receiving Uniprost had improved exercise capacity and pulmonary haemodynamics compared to placebo treated patients. ${ }^{6}$. FDA approval of this agent is currently being sought.

Prostacyclin may also be delivered via inhalation. A recently completed non-randomised trial evaluating the effect of Iloprost, a stable prostacyclin analogue delivered by inhalation, has showed very promising results. Hoeper and colleagues studied the effect of Iloprost in 24 patients with PPH who had New York Heart Association (NYHA) functional class III or IV limitations. ${ }^{7}$ Over a one year period, this group demonstrated significant improvements in exercise capacity and pulmonary haemodynamics. Iloprost is currently being evaluated in a randomised, placebo controlled, double blind study, and, if licensed, will likely be the next major addition to the armamentarium to treat PPH since Flolan was approved five years ago.

Beraprost, a chemically stable and orally active prostacyclin analogue, has also shown potential in the management of PPH. An open labelled uncontrolled dosing study of Beraprost demonstrated significant improvements in cardiopulmonary haemodynamics and NYHA functional class in 34 patients receiving this medication three times a day. A follow up study indicated that this medication may show promise in improving the survival of patients with $\mathrm{PPH}$, much like its intravenous counterpart. ${ }^{8}$ A large, multicentre phase III trial evaluating the effect of Beraprost on disease progression in patients with NYHA class II/III pulmonary arterial hypertension is currently underway and will help to answer the question of the utility and tolerability of this drug.

Nitric oxide, endothelin-1, and thromboxane Another "beneficial" endothelial derived mediator, nitric oxide (NO), is also known to inhibit pulmonary artery smooth muscle cell growth and constriction, as well as platelet aggregation. ${ }^{9}$ As with PGI2, endothelial production of NO is decreased in patients with pulmonary hypertension. ${ }^{10}$ Inhalation of $\mathrm{NO}$ in low doses can lead to pronounced, selective pulmonary vasodilation ${ }^{11}$. The long 
term efficacy of inhalation of $\mathrm{NO}$ is not known although preliminary reports are encouraging.

A second growth factor that has gained attention as possibly contributing to the development of PPH is thromboxane. Thromboxane has been shown to induce intimal proliferation as well as cause vasoconstriction and increased platelet aggregation, and is found in excess in patients with PPH. ${ }^{3}$ However, studies have been disappointing using thromboxane receptor blockers.

Endothelin-1 ((ET-1), a powerful vasoconstrictor, mitogen, and profibrotic agent, is thought to play a role in the development of intimal proliferation and vasoconstriction. This theory is supported by studies that have shown that patients with $\mathrm{PPH}$ have enhanced expression ${ }^{12}$ and increased circulation concentration ${ }^{13}$ of endothelin. The known detrimental actions of excess pulmonary endothelial ET-1 have led to trials of ET-1 receptor blockers. A recently completed randomised, placebo controlled pilot trial of bosentan, an oral dual receptor antagonist of ET-1, showed significant improvement in exercise capacity, functional class, and pulmonary haemodynamics in patients with pulmonary arterial hypertension. ${ }^{14}$

\section{Factors outside the endothelium}

Pathogenetic factors outside the pulmonary endothelium may also be important. Recent data suggest that patients with PPH may have a primary defect in certain potassium (Kv) channels in their pulmonary artery smooth muscle cells that would favour vasoconstriction and cell proliferation. ${ }^{15}$ Agents which would reverse this defect might, therefore, have great potential.

Additionally, the role of elastase in development of pulmonary hypertension has gained recent interest. Inhibition of matrix metalloproteinase was shown to induce regression of hypertrophied rat pulmonary arteries in organ culture. This was followed by a study demonstrating that elastase inhibitors can normalise pulmonary artery pressure and structure, and improve survival in rats with monocrotaline induced pulmonary hypertension. ${ }^{16}$ No human studies have been performed to date.

Circulating blood factors may be important. There is retrospective evidence that anticoagulation with warfarin is beneficial to survival, suggesting that thrombosis may play a negative role in $\mathrm{PPH}{ }^{2}$

Finally, there is research underway which could lead to the "ultimate" PPH treatment, gene replacement. It may be possible to replace a deficient PGI $2^{17}$ or $\mathrm{NO}^{18}$ synthase gene, thereby enhancing endogenous production of beneficial mediators.

Advances in the understanding of the molecular and cellular pathogenesis of $\mathrm{PPH}$ appear to be leading to easier, more effective treatments for this complicated disease process. What were previously felt to be irreversible vascular lesions may, in fact, be reversible. This possibility has ushered in an exciting new era for physicians and patients.

COLLEEN L BAILEY RICHARD N CHANNICK LEWIS J RUBIN

University of California, San Diego,

La folla Campus,

9300 Campus Point Drive/MC 7372,

La folla, CA 92037-1399, USA

lirubin@ucsd.edu

1 D'Alonzo GE, Barst RJ, Ayres SM, et al. Survival in patients with primary pulmonary hypertension. Results from a national prospective registry. Ann Intern Med 1991;115:343-9.

2 Rich S, Kaufmann E, Levy PS. The effect of high doses of calcium-channel blockers on survival in patients with primary pulmonary hypertension. $N$ Engl f Med 1992;327:76-81.

3 Christman BW, McPherson CD, Newman JH, et al. An imbalance between the excretion of thromboxane and prostacyclin metabolites in pulmonary hypertension. N Engl f Med 1992;327:70-5.

4 Barst RJ, Rubin LJ, Long WA, et al. A comparison of continuous intravenous epoprostenol (prostacyclin) with conventional therapy for primary pulmonary hypertension: The primary pulmonary hypertension study group. $N$ Engl f Med 1996;334:296-302.

5 Badesch DB, Tapson VF, McGoon MD, et al. Continuous intravenous epoprostenol for pulmonary hypertension due to the scleroderma spectrum of disease. A randomized, controlled trial. Ann Intern Med 2000;132:425-34.

6 McLaughlin VV, Hess DM, Sigman J, et al. Long term effects of UT-15 on hemodynamics and exercise tolerance in primary pulmonary hypertension. Eur Respir 7 2000;16:394s.

7 Hoeper MM, Schwarze M, Ehlerding S, et al. Long-term treatment of primary pulmonary hypertension with aerosolized iloprost, a prostacyclin analogue. N Engl f Med 2000;342:1866-70.

8 Nagaya N, Uematsu M, Okano Y, et al. Effect of orally active prostacyclin analogue on survival of outpatients with primary pulmonary hypertension. f Am Coll Cardiol 1999;34:1188-92.

9 Singh S, Evans TW. Nitric oxide, the biological mediator of the decade: fact or fiction? Eur Respir f 1997;10:699-707.

10 Giaid A, Saleh D. Reduced expression of endothelial nitric oxide synthase in the lungs of patients with pulmonary hypertension. $N$ Engl $7 \mathrm{Med}$ 1995:333:214-21.

11 Channick RN, Newhart JW, Johnson FW, et al. Pulsed delivery of inhaled nitric oxide to patients with primary pulmonary hypertension: an ambulatory delivery system and initial clinical tests. Chest 1996;109:1545-9.

12 Giaid A, Yanagisawa M, Langleben D, et al. Expression of endothelin-1 in the lungs of patients with pulmonary hypertension. $N$ Engl f $\mathrm{Med}$ 1993;328:1732-9.

13 Stewart DJ, Levy RD, Cernacek P, et al. Increased plasma endothelin-1 in pulmonary hypertension: marker or mediator of disease? Ann Intern Med 1991;114:464.

14 Channick RN, Simonneau G, Robbins IM, et al. Effects of the dual endothelin receptor antagonist bosentan in patients with pulmonary hypertension: a placebo-controlled study. Circulation 2000;102:II100.

15 Yuan XJ, Aldinger AM, Magdalena J, et al. Dysfunctional voltage-gated potassium channels in pulmonary artery smooth muscle cells of patients with primary pulmonary hypertension. Circulation 1998;98:1400-406.

16 Cowan KN, Heilbut A, Humpl $\mathrm{T}$, et al. Complete reversal of fatal pulmonary hypertension in rats by a serinc elastase inhibitor. Nat Med 2000;6:698-702

17 Geraci MW, Gao B, Shepherd DC, et al. Pulmonary prostacyclin synthase overexpression in transgenic mice protects against development of hypoxic pulmonary hypertension. $\mathcal{F}$ Clin Invest 1999;103:1509-15.

18 Campbell AI, Kuliszewski MA, Stewart DJ. Cell-based gene transfer to the pulmonary vasculature: endothelial nitric oxide synthase overexpression inhibits monocrotaline-induced pulmonary hypertension. Am f Respir Cell Mol Biol 1999;21:567-75. 